\title{
Aphasic theatre or theatre boosting self-esteem
}

\author{
I Côté $^{1}$, L Getty $^{2}$ and R Gaulin ${ }^{3}$ \\ ${ }^{1,3}$ Théâtre Aphasique, 225, Sherbrooke Est \\ Montréal, Québec, CANADA \\ ${ }^{2}$ Université de Montréal, École d'orthophonie et d'audiologie \\ c.p. 6128, succursale Centre-ville, Montréal, Québec, CANADA \\ ${ }^{1,3}$ www.theatreaphasique.com, ${ }^{2}$ www.eoa.umontreal.ca
}

\begin{abstract}
Aphasia is an acquired communication disorder caused by a brain damage that can affect the ability to speak and understand, as well as to read and write. Aphasia is most commonly caused by a stroke, but it can also result from a traumatic brain injury or a tumor. Having lost normal communication skills, an aphasic victim will often hide and isolate him or herself. This can also occur as a result of a reduced level of activity following rehabilitation. To help cope with this condition and in order to help victims regain their self-esteem, the Aphasic Theatre was created in 1992. The objective was to involve interested victims in drama and theatre as a way to rehabilitating their communication skills and self-esteem. The Aphasic Theatre is today a recognized theater company which has put on plays in Quebec as well as elsewhere in Canada and Europe. There is now an accumulation of recorded evidence, from specialists, aphasic participants and their relatives, audience attending Aphasic Theatre performances as well as a study completed by ESPACE group of University of Montreal, to confirm the validity of this innovative social rehabilitation method (Le Dorze and Brassard, 1995).
\end{abstract}

\section{INTRODUCTION}

Even a mild presence of aphasia can interfere with established relationships and as a result can cause serious social isolation. Worst case situations can lead to a complete breakdown with one's surroundings. Indeed, a verbal handicap is itself a significant obstacle for an aphasic person. How can one make real social interactions when one cannot clearly express ideas, opinions, or express perception of things and events? Most aphasic victims become listeners when in a group situation because they can neither contribute to the conversation nor can they entirely understand verbal exchanges. As well as they would like to respond, words are missing and conversation changes too rapidly. Afraid of making mistakes, aphasic persons tend to avoid communication opportunities resulting voluntarily or not isolate and reduced self-esteem.

\section{APHASIC THEATRE}

In order to overcome the social isolation caused by aphasia, Anne-Marie Theroux, an actress and speechlanguage pathologist working at the Villa Medica Rehabilitation Hospital in Montreal, developed an original approach to assist the social reinsertion of aphasic people through the practice of drama and theatre. Inspired by Augusto Boal's principals and his Theatre of the Oppressed (Boal, 1978), she started using non-oral drama expression with aphasic victims to reinforce traditional methods of rehabilitation. Then she founded the Aphasic Theatre Compagny so that interested aphasic persons could become involved in communications activities in a successful and pleasant way. The main objective was to create a shared, open, welcoming and respectful environment of peers and professionals.

The Aphasic Theatre offers two types of activities:

- drama workshops without any representational aims

- theatrical play production 


\subsubsection{Objectives}

- Stimulate:

o Body, expression and speech skills

o Pragmatic skills (look, listening, speech rules)

o Cognitive skills (memory, creativity, reasoning, divergent thought)

- Encourage social interaction and break down isolation

- Develop self-confidence and encourage self-esteem

- Find alternative tools leading to improved communication

- Reinforce autonomy and self-support

- Consider as a main goal the pleasure of communicating

2.1.2 Functioning. Since 1996, the Aphasic Theatre core team consists of a speech therapist and a theatre trained specialist. This qualified partnership can quickly bring the workshops to a high level of efficiency. The participants are surrounded by professionals recognized in their field. The vocal training and exercises that requires a more clinical approach are tasks managed by the speech therapist. This person also handles aphasics victims having to deal with major dysfunctional problems. The theatre specialist focused on the play acting, training and support. Regular meetings evaluate progress and prepare the next workshop.

Aphasic participants not only include persons with language disorders but they may also have hemiplegic and apraxic conditions. Other disorders may therefore also included memory, space orientation, hyper sensibility and other problems. All these conditions are taken into consideration when preparing a workshop.

Two different types of workshops are held at Villa Medica Rehabilitation Hospital, namely:

- Act one is a workshop designed for beginners. It includes physical, vocal and memory exercises, as well as sessions based on gestures, facial expression, improvisation.

- Roll cameras! Action! Is a workshop to produce a video production. It requires reading skills, memorization, and improvisation in front of a video camera.

Each workshop is held once a week, lasts two hours each and are scheduled in the fall to spring period.

2.1.3 Accessibility. The aphasic person having completed therapy or still in a rehabilitation program can participate in the workshop sessions. Also welcome are victims with other language disabilities such as dysarthria. There are no prerequisites, no discrimination on the basis of speech abilities or other limitations, only the interest to participate.

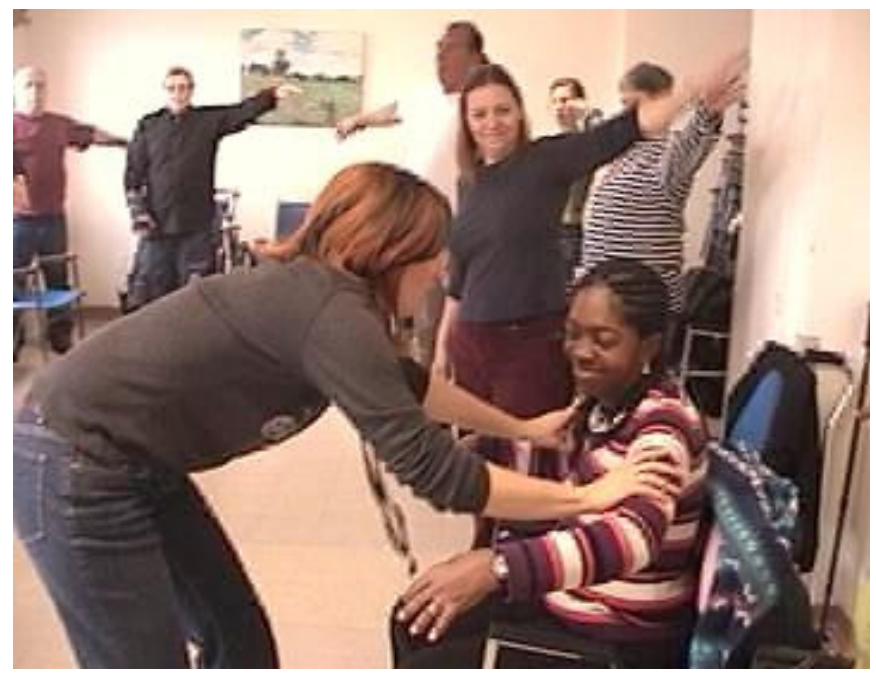

Figure 1. Dramatic art workshop. 


\subsubsection{Typical workshop planning.}

1. Arrival

2. Discussion

3. Physical warm up

4. Vocal warm up

5. Series of exercises:

-Basic skills

- Level of confidence (trust)

- Mime and expressive gesture

- Memorization-concentration

- Listening abilities-interaction

- Expression of emotions

- Exercise using the imagination

- Improvisation- character play

6. Feed back

\subsection{Theatrical Play Company}

Any aphasic person willing to spend more time as an active member of the Aphasic Theatre Compagny can become involved in this activity. It requires that the participant previously attended workshops given by the speech-language pathologist and the theatre specialist. There are no auditions but the future participant must be interested in being part of a new play project. In addition, the Director of a new play may recruit aphasic people attending workshops. The only restrictions have to do with physical endurance and capability of understanding simple instructions. In this environment there is no speech language pathologist and as such the participant must be self-sufficient.

\subsubsection{Objectives}

- Develop creativity, production and interpretation skills

- Increase self-confidence

- Acquire theatrical skills

- Develop speech abilities in front of an audience

- Encourage interaction and listening abilities

- Build a collective project

2.2.2 Play development. The quality of any play performed by the Aphasic Theatre Company is essentially related to the casting of the actors and their respective performances, courage and determination. It also relies on the great capacity of the Play Director to promote talent and to overcome limitations. There is, however, no specific formula to making a success with a theatrical play performed by aphasic persons.

The Aphasic Theatre produces its own play, in order to open acting opportunities and develop aphasic actors consistent with each person's desire to meet goals in a positive and fulfilling way. The play is intended to serve the aphasic people while modestly encouraging his or her perseverance.

Over the years, each Play Director has developed his or her methods and skills to be successful with aphasic actors in various situations, such as:

- Short scenes: work on sketches.

- Mime and spoken scenes: establish an equilibrium involving spoken roles and mime roles.

- Memorization: overcome problems as required and limit lines to be learned even though some actors could handle more lines.

- Rotation and substitution: use two castings for the same role to overcome possible scheduling conflicts (vacations, health problems). This also allows more participants to tour with the play. 
- Trust and confidence: by scheduling many rehearsals aphasic actors become more at ease with lines and play acting (entrances and exits). Surrounding the actors with stage professionals also contributes to trust and confidence.

As already noted, the play productions are especially dedicated to informing the population about aphasia as well as present victims through the role they play on stage. It does not involve attracting attention to the specific case of the actor victim.

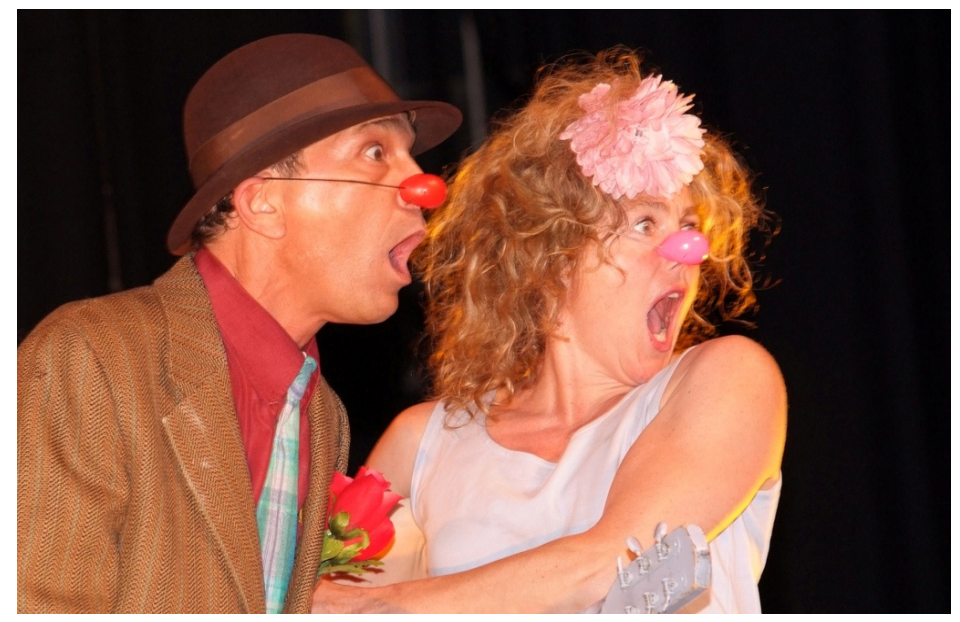

Figure 2. Terre Aphasie, directed by Isabelle Côté.

2.2.3 Production steps. First step: the process begins with identifying what the aphasic person wants to improve through an acting experience. Examples include the ability to learn more lines, develop acting abilities, play a character very different from oneself, acknowledge a talent such as singing and or dancing. For beginners, the simple experience of being introduced to the production process can be a meaningful accomplishment. This step also includes the evaluation of existing and potential abilities and skills so as not to overburden any actor.

Second step: establish the main theme around which the play action will integrate the various communication problems. Although communication is the main reason why the Aphasic Theatre exists, it is not necessary that a play only stress aphasia and one's changed life experience. It does matter, but there is more than this to explore and show as for example to deal with problems of day to day situations.

Third step: develop a scenario and script to commence the first improvisation session. The Play Director will use the improvisation sessions to push forward the creative process in an interactive way, varying actors and emotions, fashioning the play until images, sketches and scenes are established. The Director's challenge is to find a way to adapt his vision for the play with the capabilities of the aphasic actors.

Forth step: putting all the previous work together to achieve the final play version. The Play Director may come up with a text inspired by the improvisation sessions or the actors may be asked to write their own texts or the Director may rewrite a previously prepared text. Rehearsals can commence and this will be followed by further adjustments. When the play is finally performed, the full capabilities and talents of the aphasic actors are put on stage for the audience to appreciate.

\section{ADVANTAGES}

\subsection{Field Level Feedback}

After more than ten years of Aphasic Theatre activity, field evidence supports the conclusion this approach is relevant and efficient in improved aphasic person communication deficiencies, social activity and selfesteem. Feedback obtained from aphasic participants, family members, play audiences, involved theatre professionals, speech language pathologists and other people points to the value and significance of workshops and play acting as key to aphasic victim well-being. Aphasic people are quick to point out that workshops and play acting are much more than recreational activities. They result in more and better interaction with relatives and strangers and with less stress. In comparison with aphasic people who do not participate in this way, they are happier and less depressed. They also have more tools to rely on to be understood. Self-confidence is heightened and shyness diminishes. 
Being part of a theatre play is rewarding in regaining self-esteem especially if one performs in front of a live audience. The approval and congratulations that come with applause, smiles and tears can be exhilarating as well as reward for the courage, time and hard work put in. The feedback provided by aphasic actors is clear and positive. In addition, they gain a strong sense of purpose by helping to educate the public. The audience itself is better informed and is made more aware of what the aphasic person faces in his or her everyday life.

\subsection{Testimonials}

Here are some testimonials grasped among aphasic people, relatives and speech-language pathologists in touch with the Aphasic Theatre's approach:

Lise, an aphasic member of the theatre company:

I am living with aphasia and I thought that my life was over. But I was completely wrong. It is only different.

I had the opportunity to join the Aphasic Theatre. There is a great deal of laughter with a bunch of joyful people: you find comfort, you welcome new members, help others, encourage them, you create and tour. You meet other aphasic people dealing with other physical or speech disorders. Some of them are more severe than others. But one thing still remains, the ability to speak easily and spontaneously is missing. Words are there but not right away when you need them. The common goal for all of us remains in the firm desire to express our needs and ideas.

Francine, an aphasic participant's daughter:

On the 20th day of January, I saw the play «Je vous lègue ma folie». Martial, my father took part in it as an actor... I had never thought that one day my father would be on stage and perform in a theatre production... Afterwards, I was astonished by all the work done by each actor, as well as their teacher. I believe that the Aphasic Theatre is an answer to my father's needs. Now I understand why it was so essential for him to be part of it.

That very night, I understood what the message of that play is: live intensively each and every moment, and how each individual on stage had to deal with their abilities. I know, of my father's disability and after seeing the production, I was more aware of all the different types of aphasia and how challenging life is for an aphasic person... I believe that the Aphasic Theatre helped my father to break through barriers, use all his will to keep trying to talk more and have fun on stage.

Gisèle, speech-language pathologist:

Sometimes severe forms of aphasia can limit our individual clinical approach for rehabilitation. I have to recognize that we cannot always meet the needs. We do know that some aphasic people will stay with limited speech abilities but their needs to communicate and interact with their relatives still remain. The Aphasic Theatre provides a means to express them and that is priceless...

3.3 ESPACE Group Study: What effects does the participation in a theatre workshop have on individuals affected by aphasia

A study was commissioned to confirm field level feedback as well as to evaluate in an objective manner the rehabilitation results when aphasic people involve themselves in Aphasic Theatre workshops and plays. The study was carried out by ESPACE Group, from the School of Speech-Language and Audiology, University of Montreal. That research focused on the psychosocial consequences attributed to communication problems including those associated with aphasia and specifically the effect resulting from attendance and participation in Aphasic Theatre workshops and play. Financial support was provided by a scientific research fund, FQRSC, Fond Québécois de la Recherche sur la Société et la Culture. Specifically, the study examined 3 key issues:

i) Aphasic people everyday habits;

ii) Communication abilities;

iii) Relationships and interactions with relatives and social environment.

Proc. $7^{\text {th }}$ ICDVRAT with Artabilitation, Maia, Portugal, 2008 
The study methodology comprised both a quantitative and qualitative component and a before and after theatrical plays comparative component.

Four groups of aphasic people were recruited:

- aphasic actors having participated in theatrical plays;

- relatives or close persons in support contact with aphasic persons;

- aphasic persons control group;

- relatives or close persons in support contact with aphasic persons control group.

Quantitative tools were used to evaluate life habits (MHAVIE: Mesure des Habitudes de Vie, Fougerollas and Noreau (1998), communication skills (FACS: Functional Assessment of communication Skills for Adults, Lomas et al, 1989) and perception of relatives (Adjective Check List, Gough and Heilbrun, 1983). A semi-structured interview method was used for the qualitative assessment of aphasic persons and their relatives. The data was compiled separately for each of the four groups. The data was then analyzed for adaptation process.

Preliminary study show an improvement in an aphasic people's performance of everyday activities and communications in a group setting when he or she been involved in theatrical plays. At the same time, the data shows relatives or partners perceive the aphasic member in a more positive way and that they are more satisfied with his or her every day performance. The qualitative data assessment shows definite improvement of self-esteem for aphasic persons who have undertaken the theatrical play experience. The study therefore supports the conclusion that the Aphasic Theatre approach and methods are productive and effective and as such represent a valuable contribution to rehabilitation and improved self-esteem. It also suggests it is a cost/benefit and efficient means to rehabilitation and the promoting of self-esteem for aphasic persons.

\section{CONCLUSIONS}

The ESPACE Group study result support the experimentation and general conclusions previously arrived at by speech-language pathologists and theatre professionals working over more than ten years with the Aphasic Theatre. However, the study does not answer all the questions the authors hoped for. The Aphasic Theatre practitioners know that its efforts and results are more and more recognized as an alternative solution to the isolation and loss of self-esteem encountered by aphasic people. When it started its activities in 1992, it was the only institution to use drama and theatre to assist aphasic people. When it went to Nantes, France, in 1995 to present its first play, the new and innovative approach was quickly adopted in that country. The association of aphasic persons for the department of Ile de France near Paris formed its own theatre group, GAIF. At the invitation of French theatre group, the Aphasic Theatre presented in 2005 a play at the Comédie-Française. Aphasic groups in other countries, example Brazil, have also formed theatre groups and have followed the example of the Aphasic Theatre based in Montreal.

The authors believe that a more advanced study is warranted in order to gain more conclusive data and results. A new study should collect data over a longer time frame so as to better follow the adaptation experience and to better measure more meaningful long-term results. Also, a higher number of participants in each group would be invaluable to collect more data for each step of the workshop and play processes and specifically how the aphasic persons evolve.

The Aphasic Theatre and the professionals involved have done groundbreaking work since 1992. Its success in providing hope and opportunities for aphasic people is now recognized internationally. It is well established to pursue its mission of informing the public of the aphasic person's condition as well as presenting theatrical works casting aphasic persons. 


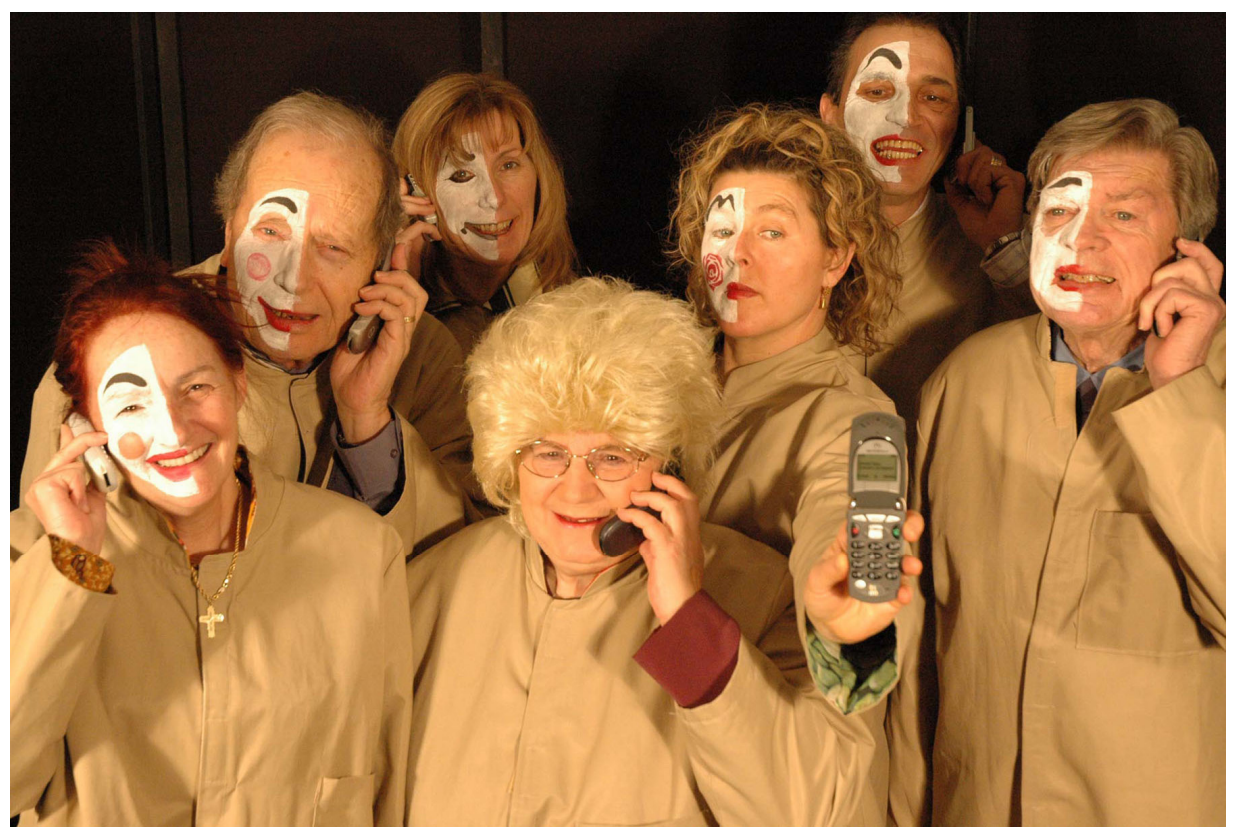

Figure 3. Métronome, directed by Richard Gaulin.

\section{REFERENCES}

1. G Le Dorze and C Brassard (1995), A description of the consequences of aphasia on aphasic persons and theirs relatives and friends, based on the WHO model of chronic diseases, Aphasiology, 9, 239-255.

2. A Boal (1978), Jeux pour acteurs et non acteurs, Paris.

3. P Fougerollas and L Noreau (1998), La Mesure des habitudes de vie. Version 3.0. Réseau international du Processus de production du Handicap. Lac St-Charles, Québec.

4. J Lomas, L Pickard, S Bester, H Elbard, A Finlayson and C Zoghaib (1989), The communicative effectiveness index: development and psychometric evaluation of a functional communication measure for adult aphasia, Journal of speech and hearing disorders, 54, 113- 124.

5. H G Gough and A B Heilbrun (1983), The Adjective Check List Manual. Palo Alto, CA: Consulting Psychologist Press. 